\title{
Prevalence and causes of blindness in the Northern Transvaal
}

\author{
PIUS J M BUCHER' AND CAREL B IJSSELMUIDEN ${ }^{2}$ \\ From the ${ }^{1}$ Department of Ophthalmology, Elim Hospital, and the ${ }^{2}$ Department of Community Health, \\ University of the Witwatersrand, Johannesburg and Elim Hospital, South Africa
}

SUMmARY During November 1985 a survey was carried out to determine the prevalence and causes of blindness in the Elim Hospital district of Gazankulu in the Northern Transvaal, South Africa, and to assess the Eye Department's effectiveness in preventing blindness. Using a random cluster sample technique, we screened 18962 of the estimated 71200 inhabitants of the district $(26.6 \%)$. We found 109 blind people. The prevalence of blindness was $0.57 \%$ (95\% confidence interval $0.46 \%-0 \cdot 68 \%)$. The main causes of blindness were senile cataract $(55 \%)$, corneal scarring due to trachoma $(10 \%)$, uncorrected aphakia $(9 \%)$, and open-angle glaucoma $(6 \%)$. There were 14 aphakic blind persons who did not have aphakia glasses (43\% of all persons operated on for cataract). Women had a significantly higher prevalence of blindness than men. After the age of 60 years the prevalence of blindness increased sharply. Women were 1.6 times less likely to have undergone cataract surgery than men. The two most effective steps to reduce the prevalence of blindness in the Elim district further are to provide aphakia glasses to all aphakic patients and to improve the accessibility of the Eye Department's surgical services.

The district served by the Elim Hospital is part of the Gazankulu 'homeland'. It is situated in the far northern part of the Transvaal Province of South Africa, just north of the tropic of Capricorn at an altitude of approximately $600 \mathrm{~m}$ above sea level. The summers are hot and winters are cool. The average rainfall is approximately $500 \mathrm{~mm}$ per year, $80 \%$ of which falls in the summer months. ${ }^{1}$

The Elim district's population is approximately 71200 people. $^{12}$ The rate of natural increase is an estimated $3.0 \%$, and $53.6 \%$ are younger than 15 years of age. Only $3.5 \%$ of the population are 65 years of age or older. ${ }^{1}$ Owing to the migrant labour system over $70 \%$ of men in the economically active age groups are absent for most of the year. ${ }^{3}$

The population of the Elim district live in 21 well defined villages. Motorised transport is available but expensive. Water is scarce and must be collected from communal standpipes or rivers. The average cash income for a family of four persons is estimated at R50-150 per month. (The price of a month's supply of maize meal, the local staple food, is R40.) There is early and late childhood malnutrition, while

Correspondence to Pius J M Bucher, MD, Augenspital, Mittlere Strasse 31, CH-4056 Basel, Switzerland. there is no (anthropometric) undernutrition in adults..$^{45}$ It is estimated that $40 \%$ of women and $60 \%$ of men over the age of 20 years are literate. ${ }^{1}$

The ophthalmic services at the Elim Hospital have a long history. ${ }^{6}$ The Ophthalmic Hospital at Elim is sufficiently equipped to deal with the diagnosis and treatment of most common eye conditions. Lid and orbit operations as well as extra and intraocular operations of the anterior segment can be performed.

The Elim Blindness Prevention Programme was started in 1972, and it consists of three interrelated activities. Preventive and promotive care is mostly provided by the volunteer Care Group (CG) members in all villages of the Elim Health Ward.' Curative care is given in the Eye Hospital and the mobile clinics by ophthalmologists and ophthalmic nurses. Rehabilitation is provided by an occupational therapist and a mobility trainer. ${ }^{89}$

Most information on the occurrence of blindness in Africa is based on hospital record reviews. ${ }^{111}$ Hospital data are not likely to be representative of the pattern of eye diseases in a population, since geographical, cultural, socioeconomic, and political factors may all influence hospital usage. ${ }^{.1}$

Available data on blindness in the Northern 
Transvaal is also limited. Earlier studies either were done more than 30 years ago $^{1213}$ or were concerned only with a specific cause of blindness, ${ }^{12}$ or were only hospital based. ${ }^{9}$ Extrapolating from hospital records, Sutter estimated that blindness prevalence in the Northern Transvaal was $1 \cdot 5-2 \cdot 0 \%{ }^{89}$

The purpose of this study was to assess accurately the prevalence and causes of blindness in the Elim Health Ward. A secondary aim was to develop a hypothesis regarding the relation between the surgical activities of Elim's Eye Hospital and the prevalence of blindness in the Elim Health Ward. This last aim would have to be achieved without the availability of baseline data and without reference to a control area owing to the absence of prior community based research and lack of resources respectively. This study was conducted during November 1985.

\section{Population and methods}

Seven of the 21 villages in the Elim district (Fig. 1) were randomly selected, and all permanent residents

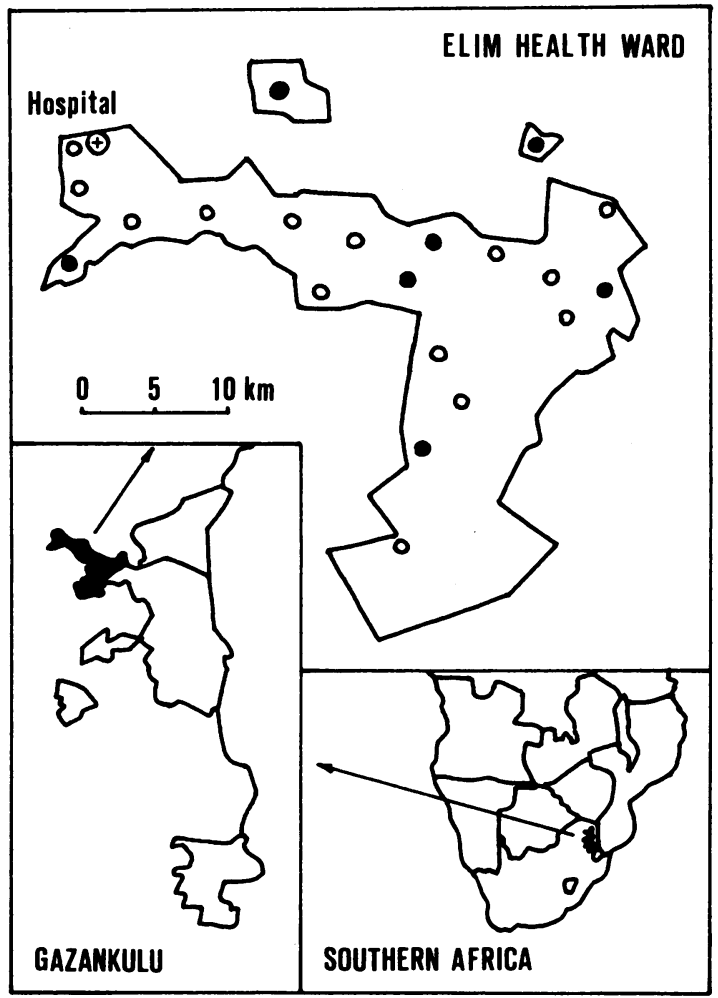

Fig. 1 Composite map of the Elim district. Study villages are indicated with solid dots. (that is, excluding migrant workers) were included in the study sample.

In the first stage of this survey CG members visited all houses in the seven selected villages. They checked the vision by asking people to count fingers at a distance of five large steps (this is always more than 3 meters) with both eyes open, wearing their own glasses (if any), outdoors in daylight. They also asked for persons who had had eye operations and for young children with 'problems of vision'. The names of all people who failed the finger counting test or had had eye surgery, and the names of all children with suspected vision problems, were recorded. Persons not present at the time of the CG member's visit were to be revisited on at least one occasion.

During the six weeks prior the survey the CG members were trained by hospital staff. Their competence was assessed by means of role plays. During the survey the CG members were supervised on a part-time basis.

In the second stage of the survey two to four days after completion of the screening the ophthalmic team (OT) visited the selected villages. The OT comprised an ophthalmologist, two ophthalmic nurses, a care group motivator, and an ambulance driver, and was based at a local school or clinic. To increase coverage further all local officials (teachers, headmen, clinic sisters, and community health workers) were also informed about the survey and were requested to bring anyone with suspected vision problems to the OT. All recorded, referred, and 'self-reporting' persons were screened by the OT. Persons whose names were recorded but who were not present at the time of the OT's visit were traced one or two days later. People who were not able to come to the OT were examined at their homes.

In this second screening phase people unable to count fingers at a distance of 3 meters (equivalent to visual acuity $3 / 60$ ) or less were identified as blind..$^{14}$ is These, together with all persons who had had an operation, constituted the final study group. Their personal and ophthalmic history was taken, and their socioeconomic status was assessed. The subject's visual acuity was tested for each eye, with and without correction, by Snellen charts. The anterior segment was examined with a torch and 5 times magnifying binocular glasses. The posterior segment was examined by direct ophthalmoscopy, and the intraocular pressure measured by Schiøtz tonometry. The visual acuity of aphakic eyes was determined with standard spheric correction, that is, $+10,+11$, or +12 dioptres.

Glaucoma was diagnosed by an intraocular tension above $21 \mathrm{mmHg}$ and a glaucomatous excavation of the papilla. Owing to the limitations of the examination methods employed under field conditions we 
could differentiate only between open-angle (deep anterior chamber), narrow-angle (shallow anterior chamber, clinical signs of acute glaucoma attacks), and secondary glaucoma (trauma, cataract operation).

Classification of blinding diagnoses was done as recommended by the WHO. ${ }^{14}$ is The most probable cause of blindness for each eye was established as recommended by the National Society for the Prevention of Blindness in the USA. ${ }^{16}$ Persons who had different causes of blindness for each eye were classified according to the most recent eye becoming blind. ${ }^{16} 17$

For reasons indicated in the discussion the study sample was treated as if it was the result of a random sampling procedure. The effects of clustering were therefore not taken into consideration when statistical calculations were done. Differences between two proportions were assessed by the standard formula. To assess differences in overall blindness prevalence in males and females, age adjusted rates were calculated from the total study sample as standard population. However, the male-female prevalence difference is not constant in all age groups, and the age adjusted rates are therefore only a crude measure of true prevalence.

In this article we differentiate between 'refractive' blindness, which is treatable by proper correction of the refractive error, and 'non-refractive' blindness, which includes all other causes of blindness. Effective blindness includes both 'refractive' and 'nonrefractive' blindness.

\section{Results}

The estimated population of the seven selected villages combined was 18962 persons, which is $26.6 \%$ of the total population of the Elim district.

The number of people identified by the CG members was 281 , of whom $270(96 \%$ ) or more (some might have used other names) were subsequently seen by the OT. An additional 151 persons were referred by village officials or were self-reporting.

In total 172 people were included in the final study group, of whom $138(80 \%)$ were identified by the CG. Of the 172 study subjects 109 were blind and 63 were not blind but had had an eye operation.

The prevalence of effective blindness in the Elim district was $0.57 \%$ (95\% confidence interval $0.46 \%$ $0 \cdot 68 \%$ ). The prevalence of 'non-refractive' blindness alone was $0.50 \%$ (95\% confidence interval $0.40 \%$ $0.60 \%)$.

Women were significantly more affected by blindness than men $(\mathrm{p}<0.0001)$ (Table 1$)$. The prevalence of blindness rose sharply after the age of 60 years in both sexes (Table 1). The average age of blind persons was 69.4 years (SD 15.3 years). The difference in the average age between males $(65 \cdot 2$ years, SD 22.3 years) and females $(71.1$ years, SD 11.6 years) was not statistically significant.

The most common causes of bilateral blindness in the Elim district were senile cataract $(55 \%)$, corneal scarring due to trachoma $(10 \%)$, uncorrected aphakia after cataract surgery $(9 \%)$, and open-angle glaucoma $(6 \%)$ (Table 2). No proper diagnoses and

Table 1 Distribution of population and blindness by age and sex

\begin{tabular}{|c|c|c|c|c|c|c|c|c|c|c|}
\hline \multirow{3}{*}{$\begin{array}{l}\text { Age } \\
\text { group }\end{array}$} & \multicolumn{4}{|c|}{ Population Elim Health Ward* } & \multicolumn{6}{|c|}{ Blindness } \\
\hline & \multicolumn{2}{|c|}{$\operatorname{Sex}(\%)$} & \multicolumn{2}{|l|}{ Total } & \multicolumn{3}{|l|}{ Cases } & \multicolumn{3}{|c|}{ Prevalence (\%) } \\
\hline & Males & Females & $n$ & $(\%)$ & Males & Females & Total & Males & Females & Total \\
\hline $0-4$ & 9.9 & $10 \cdot 3$ & 14377 & $20 \cdot 2$ & 1 & & 1 & 0.05 & & $\overline{0.03}$ \\
\hline 5-9 & $9 \cdot 1$ & $9 \cdot 1$ & 12953 & $18 \cdot 2$ & & & & & & \\
\hline $15-19$ & $4 \cdot 2$ & $5 \cdot 4$ & 6830 & 9.6 & & 1 & 1 & & $0 \cdot 10$ & 0.06 \\
\hline $20-24$ & 1.6 & $4 \cdot 7$ & 4481 & $6 \cdot 3$ & 1 & & 1 & 0.33 & & 0.08 \\
\hline $25-29$ & $1 \cdot 1$ & $4 \cdot 5$ & 3982 & $5 \cdot 6$ & & & & & & \\
\hline $30-34$ & 0.9 & 3.4 & 3057 & $4 \cdot 3$ & & & & & & \\
\hline $35-39$ & 0.9 & $3 \cdot 0$ & 2772 & 3.9 & 1 & 1 & 2 & 0.60 & $0 \cdot 17$ & 0.27 \\
\hline $40-44$ & 0.8 & $2 \cdot 4$ & 2273 & $3 \cdot 2$ & 1 & & 1 & 0.64 & & $0 \cdot 16$ \\
\hline $45-49$ & 0.9 & $2 \cdot 3$ & 2273 & $3 \cdot 2$ & & & & & & \\
\hline $50-54$ & 0.7 & $1 \cdot 8$ & 1775 & $2 \cdot 5$ & 1 & 3 & 4 & 0.69 & 0.89 & 0.83 \\
\hline $60-64$ & 0.6 & 1.4 & 1419 & $2 \cdot 0$ & 1 & 8 & 9 & 0.85 & $3 \cdot 18$ & 2.43 \\
\hline $65-69$ & 0.5 & 0.8 & 921 & $1 \cdot 3$ & 4 & 16 & 20 & $4 \cdot 23$ & $10 \cdot 91$ & $8 \cdot 31$ \\
\hline $70-74$ & 0.4 & 0.6 & 707 & 1.0 & 4 & 16 & 20 & $5 \cdot 60$ & $12 \cdot 78$ & $10 \cdot 14$ \\
\hline $75+$ & 0.4 & 0.8 & 849 & $1 \cdot 2$ & 14 & 33 & 47 & $16 \cdot 42$ & $22 \cdot 33$ & $20 \cdot 15$ \\
\hline Total & $40 \cdot 5$ & 59.5 & 71190 & $100 \cdot 0$ & 30 & 79 & 109 & & & \\
\hline \multirow{2}{*}{\multicolumn{5}{|c|}{$\begin{array}{l}\text { Crude blindness prevalence } \\
\text { Age adjusted blindness prevalence }\end{array}$}} & & & & 0.39 & 0.70 & 0.57 \\
\hline & & & & & & & & 0.44 & 0.64 & \\
\hline
\end{tabular}

*Excluding migrant workers. Institute of Development Studies. ${ }^{1}$ 
Table 2 Aetiology of blindness

\begin{tabular}{|c|c|c|c|c|}
\hline Aetiology: WHO code, clinical entity & Males & Females & Total & $\begin{array}{l}\text { Percentage } \\
\text { of all } \\
\text { blindness }\end{array}$ \\
\hline \multicolumn{5}{|l|}{ Infection } \\
\hline 271.0 Corneal scar (trachoma) & 1 & 10 & 11 & $10 \cdot 09$ \\
\hline 369.0 Undefined blindness (both eyes) (trachoma) & & 1 & 1 & 0.92 \\
\hline \multicolumn{5}{|l|}{ Injury } \\
\hline 365.6 Secondary glaucoma (trauma) & & 1 & 1 & 0.92 \\
\hline 377.1 Optic nerve atrophy (trauma) & 1 & & 1 & 0.92 \\
\hline 369.0 Undefined blindness (both eyes) (trauma) & 1 & 1 & 2 & 1.83 \\
\hline \multicolumn{5}{|l|}{ Neoplasm } \\
\hline \multicolumn{5}{|l|}{ Systemic } \\
\hline 271.0 Corneal scar (vitamin A deficiency) & 2 & 1 & 3 & $2 \cdot 75$ \\
\hline \multicolumn{5}{|l|}{ Degeneration } \\
\hline 371.4 Corneal, degeneration (cataract operation) & & 1 & 1 & 0.92 \\
\hline 371.6 Keratoconus & & 1 & 1 & 0.92 \\
\hline 366.1 Senile cataract & 13 & 47 & 60 & $55 \cdot 05$ \\
\hline 379.3 Aphakia (dislocation of the lens) & & 1 & 1 & 0.92 \\
\hline 379.3 Aphakia (cataract operation) & 4 & 6 & 10 & $9 \cdot 17$ \\
\hline 363.4 Choroid degeneration & 1 & 1 & 2 & 1.83 \\
\hline 362.5 Drusen maculopathy & 1 & & 1 & 0.92 \\
\hline 365.1 Open-angle glaucoma & 4 & 3 & 7 & $6 \cdot 42$ \\
\hline 379.2 Vitreous opacities (cataract operation) & & 2 & 2 & 1.83 \\
\hline \multicolumn{5}{|l|}{ Prenatal influence } \\
\hline 743.1 Microphthalmos & 1 & & 1 & 0.92 \\
\hline \multicolumn{5}{|l|}{ Cause not known } \\
\hline 360.4 Phthisis bulbi & & 1 & 1 & 0.92 \\
\hline 271.0 Corneal scar & 1 & & 1 & 0.92 \\
\hline 377.1 Optic nerve atrophy & & 1 & 1 & 0.92 \\
\hline 369.0 Undefined blindness (both eyes) & & 1 & 1 & 0.92 \\
\hline Total & 30 & 79 & 109 & 100 \\
\hline
\end{tabular}

aetiology could be established in four persons (4\%). In 41 blind persons (38\%) a different aetiology in each eye was found. The relative importance of the causes of blindness was not affected by classification on eyes as compared with classification on persons.

The difference in prevalence of senile cataract between men and women was not statistically significant $(p=0 \cdot 14)$. Men were 1.6 times more likely to have been operated on for cataract $(p=0.0455)$. Only $37 \%$ of persons blinded by senile cataract were operated on (Table 3). Blindness due to trachoma was virtually confined to women over the age of 65

Table 3 Distribution of blinding senile cataract and aphakia

\begin{tabular}{|c|c|c|c|}
\hline & $\begin{array}{l}\text { Males } \\
(n=26)\end{array}$ & $\begin{array}{l}\text { Females } \\
(n=64)\end{array}$ & $\begin{array}{l}\text { Total } \\
(n=90)\end{array}$ \\
\hline Not operated on & $1350 \%$ & $4469 \%$ & $5763 \%$ \\
\hline Operated (aphakic) & $1350 \%$ & $2031 \%$ & $3337 \%$ \\
\hline Blind (with glasses) & $0 \quad 0 \%$ & $35 \%$ & $33 \%$ \\
\hline Not blind with glasses & $1142 \%$ & $1320 \%$ & $2427 \%$ \\
\hline Have no glasses* & $415 \%$ & $914 \%$ & $1315 \%$ \\
\hline Have own glasses & $727 \%$ & $46 \%$ & $1112 \%$ \\
\hline Not blind without glasses & $28 \%$ & $46 \%$ & $67 \%$ \\
\hline
\end{tabular}

*Three of these persons were classified with another cause of blindness than aphakia. years. Of all persons operated on for entropion $92 \%$ were women. The prevalence of blindness and the number of operations due to glaucoma was similar in males and females.

There were 17 study subjects who had had a cataract operation and were not blind, 14 with a previous entropion operation and seven with a previous glaucoma operation who were not blind in the operated eye but blind in the other eye. On the assumption that at the time of the survey these persons would have been blind without operation the total number of blind persons in our study sample would have been 147 and the blindness prevalence $0.77 \%$ (95\% confidence interval $0.64 \%-0.90 \%$ ). Compared with the actual blindness prevalence the effect of the ophthalmic surgical activities on the nonrefractive and effective blindness prevalence in the Elim area has at best been a reduction of $26 \%$ and $35 \%$ respectively.

However, on the assumption that at the time of this study all persons at present blind from senile cataract, entropion (trachoma), and glaucoma would not have been blind if they had had eye surgery, the number of blind persons in our sample would have been only 20 . The blindness prevalence would then have been $0.11 \%$ (95\% confidence interval $0.06 \%$ $0 \cdot 16 \%$ ). Therefore only $30 \%$ of cases of blindness 
which could have been prevented or cured by an ophthalmic operation were in fact reached.

\section{Discussion}

To obtain reliable estimates of the blindness prevalence in the Elim population 18962 people were screened. The screening of such a large number of people with only a few health professionals was possible only with the help of volunteer health workers (CG). The time and organisation needed to prepare them adequately for this survey forced us to keep the number of clusters to a minimum. Since the Elim district is relatively homogeneous in respect of population, geography, income distribution, and provision of health services, we do not think that the small number of clusters will compromise the results of the study. The results of this study are therefore probably representative of the whole Elim district.

The preparation time given to the CG was only six weeks, which is a relatively short time in the local context. In spite of this they identified $80 \%$ of all people included in this study. We cannot be certain how many blind people were not seen by the OT. We can only presume that the CG did visit all homes in their village and made follow-up visits to contact absentees. The respectability of the CG and the local health service in general make it unlikely that many blind persons were missed. Although the results of this study should technically be considered as 'minimum-estimates', we think that they are in fact a fair representation of the actual situation in the Elim district.

The blindness prevalence in the Elim district is lower than the prevalence in most other subSaharan African countries. ${ }^{18-22}$ Differences in methodology between these studies and complete absence of onchocerciasis (in some African countries responsible for $12 \%-37 \%$ of all cases of blindness ${ }^{10}$ ) may partly explain this.

Blindness affects mainly those above 60 years of age, especially women. The excess risk of blindness

Table 4 List of five main causes of blindness in Elim district 1973 and 1985

\begin{tabular}{|c|c|c|c|}
\hline \multicolumn{2}{|l|}{$\begin{array}{l}1973^{*} \\
\text { Hospital based data }\end{array}$} & \multicolumn{2}{|l|}{$\begin{array}{l}1985 \\
\text { Population based data }\end{array}$} \\
\hline Diagnosis & $\%$ & Diagnosis & $\%$ \\
\hline Cataract & 50 & Cataract & 55 \\
\hline Glaucoma & 19 & Trachoma & 10 \\
\hline Trachoma & 7 & Aphakia/no glasses & 9 \\
\hline Leukoma-staphyloma & 5 & Glaucoma & 6 \\
\hline Corneal degeneration & 3 & $\begin{array}{l}\text { Corneal scar } \\
\text { (vitamin A deficiency) }\end{array}$ & 3 \\
\hline
\end{tabular}

*See Sutter. ${ }^{9}$ in women is largely explained by blinding trachoma and untreated senile cataract. The reasons why blinding trachoma affects mostly women have been discussed earlier. ${ }^{9}$ The lower literacy rate in women may explain the higher proportion of untreated senile cataract in women. The slightly higher average age of women may also be an explanation for the higher prevalence of degenerative diseases and diseases depending on repeated exposure to a noxious influence or agent.

In 1973 a hospital based blindness study was done in the Elim area. ${ }^{9}$ The one notable difference between causes of blindness in 1973 and 1985 is glaucoma (Table 4). The completely different methodology of the two studies might be the reason for this.

A surprise finding was that uncorrected aphakia after cataract surgery was the third most common cause of blindness. The reasons for this were not studied, but several factors might play a part, such as loss of glasses, inability to afford glasses, reasonable vision by the second eye at the time of first cataract surgery, or no need for glasses because of illiteracy and life style. To our knowledge it has not been reported earlier that uncorrected aphakia is a major cause of blindness. However, noting the similarities in health and health services between the Elim district and other third world areas, we would speculate that this cause of blindness may not be limited to the Elim district alone.

Surgical interventions by Elim Hospital's Eye Department have probably reduced blindness prevalence, but the effectiveness is low. One explanation might be the relative inaccessibility of the Eye Hospital's services. Geographical, economic, social, cultural, and political (borders) factors may all contribute to the inaccessibility. ${ }^{23}$ The exact causes will have to be studied carefully, since it is clear from this study that the most significant contribution of Elim Hospital's Eye Department to the Blindness Prevention Programme in the short term is to operate on a much greater proportion of those people blinded by senile cataract and to provide aphakia glasses to all aphakic persons.

\section{References}

1 Institute of Development Studies. A development framework for Gazankulu. Pretoria: Rand Afrikaans University, 1983.

2 Population census 1985. Pretoria: Department of Statistics, 1985.

3 Ijsselmuiden CB. The nutritional status of inhabitants of northern Gazankulu and the response of the health services. SALDRU: School of Economics, University of Cape Town, 1984: paper 208.

4 Ijsselmuiden CB. The nutritional status of children under the age of 5 years in northern Gazankulu. S Afr Med J 1984; 65: 346-7.

5 Ijsselmuiden CB. Nutritional status and blood pressures of adults in northern Gazankulu. $S$ Afr Med J 1985; 67: 773-5.

6 Bucher PJM. Ten years of ophthalmic nursing at the Elim Hospital. Imfama 1986; 26: 5-6. 
7 Sutter EE, Ballard RC. A community approach to trachoma control in the northern Transvaal. S Afr Med J 1978; 53: 622-5.

8 Sutter EE. Training of eye care workers and their integration in Gazankulu's comprehensive health service. Soc Sci Med 1983; 17: 1809-12.

9 Sutter EE. Blindness among South African negroes. $S$ Afr Arch Ophthalmol 1973; 1: 105-15.

10 International Agency for the Prevention of Blindness. World blindness and its prevention. Oxford: Oxford University Press, 1980.

11 Goldstein $\mathrm{H}$. The reported demography and causes of blindness throughout the world. Adv Ophthalmol 1980; 40: 1-99.

12 Amies C, Murray NL, Scott JG, Warren RStH. Trachoma in the South African Bantu. S Afr Med J 1952; 26: 362-3.

13 Amies CR, Loewenthal LA, Murray NL, Scott JG. Blindness in the Bantu S Afr Med J 1953; 27: 593-7.

14 World Health Organisation. International classification of diseases. 9th revision. Geneva: World Health Organisation, 1975.

15 World Health Organisation. Guidelines for programmes for the prevention of blindness. Geneva: World Health Organisation, 1979.

16 National Society for the Prevention of Blindness. Manual on use of the NSPB standard classicification of causes of severe vision impairment and blindness. New York: National Society for the Prevention of Blindness, 1966.

17 Goldstein H, Goldberg ID, Rogot E, Moorhead HB. Reported incidence of blindness by cause in 1963 . Sightsaving $\operatorname{Rev} 1964 ; 34$ : 214-33.

18 Shukla SM. Eye diseases and control of blindness in Zambia. Soc Sci Med 1983; 17: 1781-3.

19 Kinabo N. Eye diseases and services in Tanzania. Soc Sci Med 1983; 17: 1767-72.

20 Whitfield R, Schwab L, Bakker NJA, Bisley GG, Ross-Degnan D. Cataract and corneal opacity are the main causes of blindness in the Samburu tribe of Kenya. Ophthalmic Surg 1983; 14: 13944.

21 Bhar IS, Kasin S, Gall J, Pugh RNH, Bradley HM. Malumfashi endemic diseases research project XVIII. Ann Trop Med Parasitol 1982; 76: 243-5.

22 Tizazu T, Mburu FM. Prevalence and causes of vision loss in southern Sudan. Soc Sci Med 1983; 17: 1785-8.

23 Bucher PJM. Analyse der Anstrengungen zur Verminderung der Blindheit in Gazankulu/Südafrika. Klin Monatsbl Augenheilkd 1987; 190: 372-6.

Accepted for publication 17 August 1987. 